\title{
An Experimental Study of Electrical Appliances Consumption Using Panel Meter Data
}

\author{
Esebi A. Nyari1,2*, Marcel Castro-Sitiriche ${ }^{1,3}$, Seungyong Eugene Park ${ }^{1}$ \\ ${ }^{1}$ Department of Material Energy and Science Engineering, The Nelson Mandela African Institution of Science and Technology, \\ Arusha, Tanzania \\ ${ }^{2}$ Department of Mechanical Engineering, Dar es Salaam Institute of Technology, Dar es Salaam, Tanzania \\ ${ }^{3}$ University of Puerto Rico, Mayagüez Campus, Mayagüez, PR, USA \\ Email: *aloise@nm-aist.ac.tz
}

How to cite this paper: Nyari, E.A., Castro-Sitiriche, M. and Park, S.E. (2017) An Experimental Study of Electrical Appliances Consumption Using Panel Meter Data. Journal of Power and Energy Engineering, 5, 132-144.

https://doi.org/10.4236/jpee.2017.59011

Received: August 4, 2017

Accepted: September 26, 2017

Published: September 29, 2017

Copyright $\odot 2017$ by authors and Scientific Research Publishing Inc. This work is licensed under the Creative Commons Attribution International License (CC BY 4.0).

http://creativecommons.org/licenses/by/4.0/

\begin{abstract}
The present study uses power data from panel meter connected to the micro-grid to identify electrical energy consumption of the school appliances and their behavior in both warm-up, standby and active operation states. Before the conduction of experiments a load auditing of the school appliances was carried out by reading the rated power of each device (e.g. photocopy machine, printer, and fridge). The captures of this kind of information were essential as it provides a starting point to determine energy use of each appliance and hence simplify the process of identification. The electric parameters such as active power, reactive power and current were used to analyze the behavior of electrical appliances in all states. Experimental results show that, both active and reactive power were found to be high for old Canon photocopy machine as compared to new Canon photocopy machine. Another experiment reveals that printing one copy by using HP laser printer consumes about $700 \mathrm{~W}$, while photocopying one copy with new Canon machine utilizes approximately $1100 \mathrm{~W}$. This study concludes that new photocopy machine consumes more electric energy in warm-up state as compared to other states (standby and active operation states). Future work is to develop an algorithm for demand side management strategies which will enable efficient utilization of the electric energy from the micro-grid and hence bring the intended energy impact to the school.
\end{abstract}

\section{Keywords}

Power Load Pattern, Load Identification, Active Power and Reactive Power

\section{Introduction}

Nowadays, identification of electrical appliance use from electricity meter panels 
has become an area of study on its own due to environmental and economic issues [1]. Accurate and reliable electric load identification and monitoring provide critical information that enables households to effectively manage their electric loads [2] [3] [4] [5]. A proper load identification system can help increase system efficiency by reducing the energy consumption and thus promoting greener energy use [6] [7] [8].

Over the past twenty years, many approaches have been proposed to monitor and identify electric loads. These methods can be broadly divided into two main categories: transient state and steady state [9] [10]. In case of transient, the primary approach of load separation is based on identification of state transitions which in most cases is done by the ON/OFF transition identification [1]. Thus, transient behavior of a typical load is intimately related to the physical task that the load performs [11] [12] [13]. In contrast, method based on steady state features is derived using constant or periodical signals when the electrical loads operate under a stable state [9]. In comparison with steady state signatures, the transient behavior of major appliances is found to be distinct and their features are less overlapping [4]. Regardless of the electrical parameters chosen to create the load signatures, the recognition algorithm can operate using three different approaches: analyzing the transient characteristics (the period of time when the load is turned ON or OFF), the steady state characteristics or a combination of both [14]. Guzel and Ustunel [15], suggested that the use of both transient and steady states can increase the possibility of identifying which load type is turned "ON", since single state signature has its own limitation. Thus, this study considers both warm-up and standby states to determine the behavior of different electrical appliances at Ngarenanyuki secondary school. On the other hand, traditional load signature studies and disaggregation research focused on macro load signature, such as real and reactive power [16]. Therefore, this work also uses active and reactive power plotted in the P-Q plane to identify the turn ON and OFF of school electrical appliances.

\section{Methods}

In this study the following methods were used; load assessment, load identification experiment, and load identification analysis.

\subsection{Description of Ngarenanyuki Energy Systems}

This study was conducted at the Ngarenanyuki Secondary School, which use a micro-grid hybrid generation to power the school. Figure 1 shows the layout of the main buildings in the school.

Figure 2 illustrates the layout of the currently installed hybrid power systems, which include micro hydro power plant, solar PV, diesel generator and battery backup. The architecture of the apparatus is composed by: 1) a conversion switchboard (Q1) which considers the new installation of PV and battery bank system and the bi-directional Interface Converter; and 2) a distribution switchboard (Q2) able to work on two bus bars, integrating programmable logic controller (PLC) 


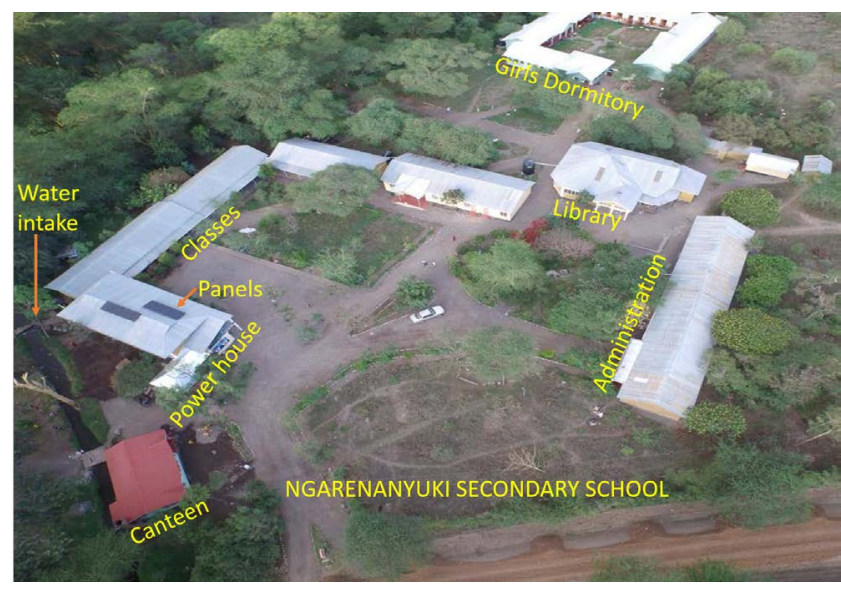

Figure 1. Layout of Nganarenanyuki secondary school.

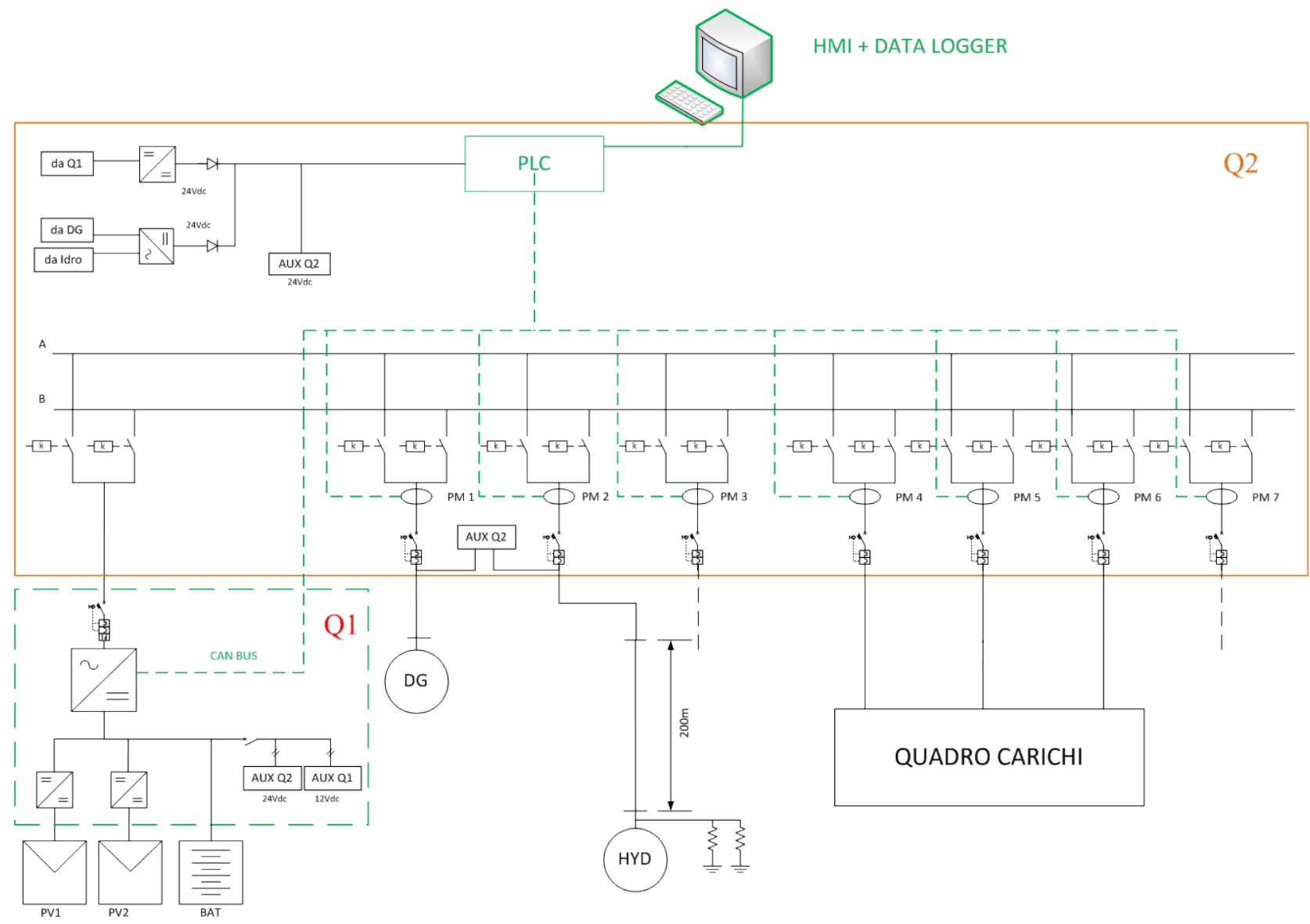

Figure 2. Hybrid micro-grid configuration [17].

system, panel meters, and local user interface in order to manage the power flow control strategies from the power sources.

\subsection{Load Assessment}

Energy auditing is one way to obtain accurate and objective assessments of how to achieve savings [18]. Therefore, before performing load identification expe- 
riments, the first thing was to assess the electrical appliances of the school. The actual appliances of each load were identified and recorded to the energy assessment sheet. The following information was recorded to that sheet; type of appliance, model, size, quantity, rated power/voltage/current. This energy audit information was used as a starting point for the load identification analysis.

\subsection{Load Identification}

In load identification method, the key step is how to get the signatures of sample [2]. The electrical loads often present unique characteristics in the electric signals (i.e. voltage, current, and power). Such load characteristics provide a viable mean to identify the type of a load (e.g. PC, heater, lamp) and its operational status (e.g. active, ready, stand by) by analyzing the electric signals [9]. To classify the load signatures some of its features are responsible like current waveform $(\mathrm{CW})$, active/reactive power (PQ), harmonics (HAR), instantaneous admittance waveform (IAW), instantaneous power waveform (IPW), eigenvalues (EIG), and switching transient waveform (STW) [19]. Methods to detect electrical loads through voltage, current and power measurements have been proposed by various researchers [9]. In this study the data consisting of the active power, reactive power, voltage, current and frequency signals were acquired from the meter panel. The analysis was mainly based on active power, reactive power and current. The voltage signal was not used as a parameter for load identification, as the voltage variations were negligible for the most part and in due course do not affect the identification results [14].

\subsubsection{Experimental Setup}

The Ngarenanyuki Secondary School blocks are divided into three loads. Load 1 includes administration, classrooms, library, and rest house blocks. Load 2 is connected to teacher's houses and girls dormitory, whereas load 3 power both kitchen and canteen blocks. In this experiment only load 1 (administration and classroom blocks) and load 3 (canteen blocks) were studied. The following electrical appliances were considered; lights, Tube lights (18 W and $36 \mathrm{~W})$, photocopy machine $(1000 \mathrm{~W})$, printer $(600 \mathrm{~W})$, freezer $(1500 \mathrm{~W})$, desktop and laptop computer $(90 \mathrm{~W})$.

\subsubsection{Experimental Procedure}

During the experiment other blocks were switched OFF at the main switch to obtain the reading of electric energy consumption for the respective block only, as shown in Figure 3. Each experiment was video recorded in order to recall the starting and ending time of the experiment. After all experiments were completed, the energy data was downloaded from the meter panel.

\section{1) Administration Block Experiments}

In this block three independent experiments were carried out. The first experiment explores the variation of electric power consumption when some of the appliances are turned $\mathrm{ON}$ and $\mathrm{OFF}$ as shown in experimental procedure $\mathrm{Ta}$ ble 1 with transitions highlighted in red. Second experiment (Table 2), involve 


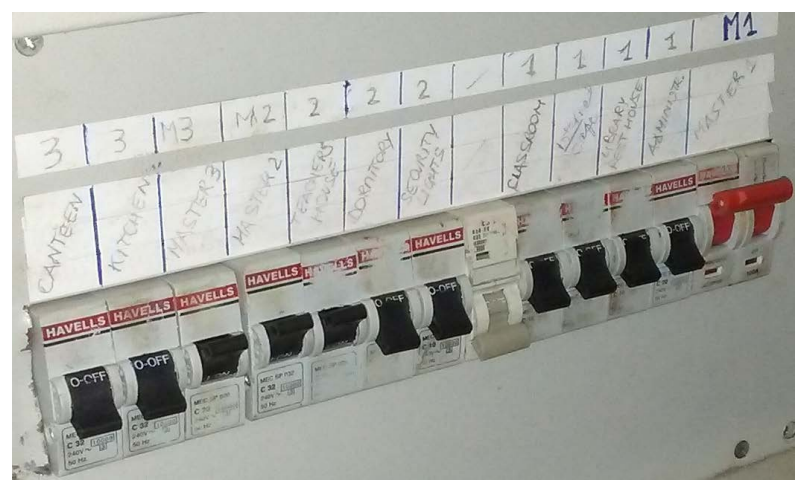

Figure 3. Ngarenanyuki micro-grid system main switch board.

Table 1. Switching ON and OFF appliances.

\begin{tabular}{ccccccccccc}
\hline Appliance & $\mathbf{1}$ & $\mathbf{2}$ & $\mathbf{3}$ & $\mathbf{4}$ & $\mathbf{5}$ & $\mathbf{6}$ & $\mathbf{7}$ & $\mathbf{8}$ & $\mathbf{9}$ & $\mathbf{1 0}$ \\
\hline Tube Light 1 & ON & ON & ON & ON & ON & ON & ON & ON & ON & ON \\
Tube Light 2 & ON & ON & ON & ON & ON & ON & ON & ON & ON & ON \\
Tube Light 3 & OFF & ON & ON & ON & OFF & OFF & OFF & OFF & OFF & OFF \\
Monitor & OFF & OFF & OFF & OFF & OFF & ON & ON & OFF & OFF & OFF \\
Acer PC Tower & OFF & OFF & OFF & OFF & OFF & OFF & ON & ON & OFF & OFF \\
Latitude E6410 & ON & ON & OFF & ON & ON & ON & ON & ON & ON & ON \\
Laptop & & & & & & & & & & \\
Internet Sever & ON & ON & OFF & ON & ON & ON & ON & ON & ON & ON \\
\hline
\end{tabular}

Table 2. Photocopy and printer experiment.

\begin{tabular}{cccccccccc}
\hline Appliance & $\mathbf{1}$ & $\mathbf{2}$ & $\mathbf{3}$ & $\mathbf{4}$ & $\mathbf{5}$ & $\mathbf{6}$ & $\mathbf{7}$ & $\mathbf{8}$ & $\mathbf{9}$ \\
\hline Tube Light 1 & ON & ON & ON & ON & ON & ON & ON & ON & ON \\
Tube Light 2 & ON & ON & ON & ON & ON & ON & ON & ON & ON \\
Tube Light 3 & OFF & ON & ON & ON & ON & ON & ON & ON & OFF \\
$\begin{array}{c}\text { Acer PC Tower } \\
\text { (Plus Monitor) }\end{array}$ & ON & ON & ON & ON & ON & ON & ON & ON & ON \\
HP Laser Printer & OFF & OFF & ON & ON & ON & PRINT & ON & OFF & OFF \\
Photocopy m/c-Canon & OFF & OFF & OFF & ON & COPY & ON & OFF & OFF & OFF \\
Latitude E6410 Laptop & ON & ON & ON & ON & ON & ON & ON & ON & ON \\
Internet Router & ON & ON & ON & ON & ON & ON & ON & ON & ON \\
\hline
\end{tabular}

turning ON some appliances, and then making a photocopy and printing. For the third experiment the photocopy machine was switched ON for about 10 seconds and then commanded to make 10 copies before being switched OFF as shown in experimental procedure Table 3.

\section{2) Canteen Experiment}

In this block only one experiment was conducted, to identify the variation of electric power and current of the lights and freezer when switched ON and OFF as shown in experimental procedure Table 4. 
Table 3. Photocopying experiment.

\begin{tabular}{|c|c|c|c|c|c|c|c|c|c|c|c|c|}
\hline Appliance & 1 & 2 & 3 & 4 & 5 & 6 & 7 & 8 & 9 & 10 & 11 & 12 \\
\hline Tube Light & $\mathrm{ON}$ & ON & ON & ON & ON & ON & ON & ON & ON & ON & ON & $\mathrm{ON}$ \\
\hline Tube Light & $\mathrm{ON}$ & ON & ON & ON & ON & ON & ON & ON & ON & ON & ON & ON \\
\hline MacBook Laptop & $\mathrm{ON}$ & ON & ON & ON & ON & ON & ON & ON & ON & ON & ON & $\mathrm{ON}$ \\
\hline $\begin{array}{l}\text { Latitude E6410 } \\
\text { Laptop }\end{array}$ & OFF & OFF & OFF & OFF & OFF & OFF & OFF & OFF & OFF & OFF & OFF & OFF \\
\hline Acer PC Tower & OFF & OFF & OFF & OFF & OFF & OFF & OFF & OFF & OFF & OFF & OFF & OFF \\
\hline Printer & OFF & OFF & OFF & OFF & OFF & OFF & OFF & OFF & OFF & OFF & OFF & OFF \\
\hline Printer \& Scanner & OFF & OFF & OFF & OFF & OFF & OFF & OFF & OFF & OFF & OFF & OFF & OFF \\
\hline Photocopy M/C & $\mathrm{ON}$ & COPY & COPY & $\mathrm{COPY}$ & $\mathrm{COPY}$ & COPY & $\mathrm{COPY}$ & $\mathrm{COPY}$ & COPY & COPY & $\mathrm{COPY}$ & OFF \\
\hline Internet Router & $\mathrm{ON}$ & ON & ON & ON & ON & ON & ON & ON & ON & ON & ON & ON \\
\hline Latitude E6410 & ON & ON & ON & ON & ON & ON & ON & ON & ON & ON & ON & ON \\
\hline
\end{tabular}

Table 4. Switching ON and OFF appliances in canteen.

\begin{tabular}{ccccccccc}
\hline Appliance & $\mathbf{1}$ & $\mathbf{2}$ & $\mathbf{3}$ & $\mathbf{4}$ & $\mathbf{5}$ & $\mathbf{6}$ & $\mathbf{8}$ \\
\hline Lights & OFF & ON & OFF & OFF & OFF & OFF & OFF \\
Freezer & OFF & OFF & OFF & ON & OFF & ON & OFF \\
\hline
\end{tabular}

\section{Experimental Results}

The present work used micro-grid power data to analyze and identify the ON/OFF status of loads and the operation behavior of school electrical appliances such as lights, photocopy machine, printer and freezer. It is worth mentioning here that, in the administration block, there is an uninterruptible power supply backup (UPS) connected, which is expected to alter the meter panel reading. The experiments were conducted with and without backup UPS connection. However, the present analysis considers the experimental results without backup UPS only, which gives the actual variations of power consumption. The results of both composite load (CL) and load signature analysis are presented in this section.

\subsection{Warm-Up and Standby State Results}

The patterns for both switching ON and switching OFF current and active power have been acquired in order to analyze the waveforms and extract unique appliance specific features as shown in this section. The top graphs in Figures 4-7 shows the current consumed by different appliances and the bottom plots show the active power consumption.

Figure 4 presents the current and active power for incandescent and tube lights. Current waveform of tube light is slightly uniform as compared to current waveform of incandescent light. Furthermore, it can be observed that the warm-up current and active power is higher for incandescent light as compared to tube light. 
Incandescent light
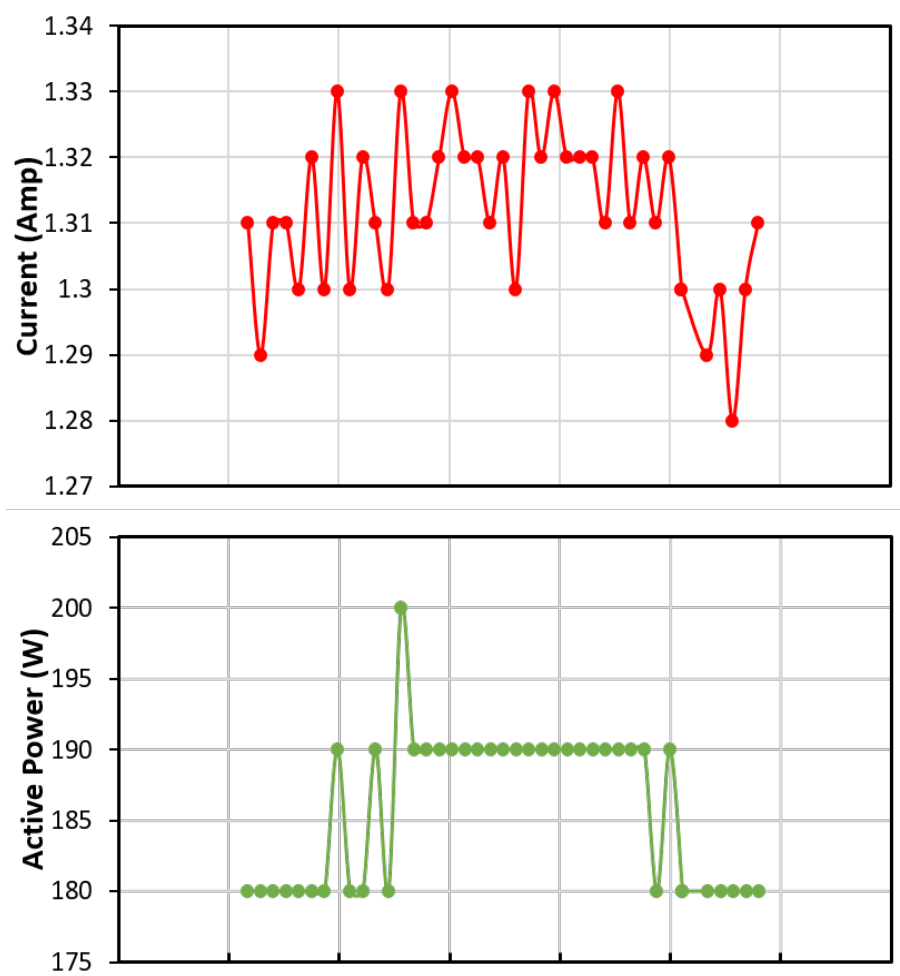

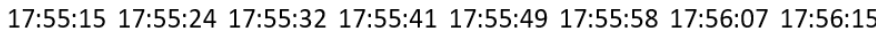

Time
Tube light
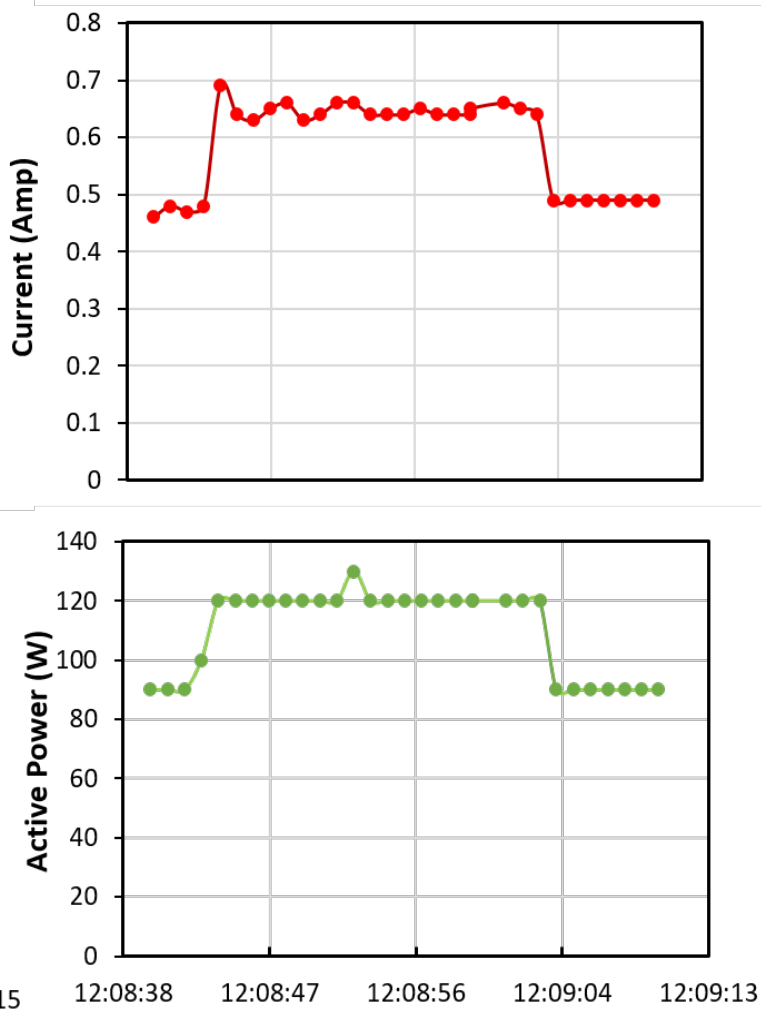

Time

Figure 4. Current and active power for lights.

Looking at Figure 5, load pattern for desktop computer is contrasted with the HP printer. HP printer draws more current and active power when turned $\mathrm{ON}$ as compared to desktop computer. On the other hand, the difference between current and active power waveform for both appliances are hardly noticeable denoting a fairly constant voltage. However, the load pattern of the two appliances differs considerably.

Figure 6 presents the comparison of load pattern for new and old photocopy machines. Although the two photocopy machines have slightly different loads, both have similar patterns in current and active power spectrum. Looking in the Figure 6 power consumption is higher for the old photocopy machine as compared to new photocopy machine. There are slight increase of current and active power for second switch $\mathrm{ON}$ and OFF, as compared to first action

Figure 7 presents behavior of freezer when switched ON and OFF twice. Its event detection is observed by the peak values of both current and active power. It is noteworthy in the plot that the waveform responses are slightly different for the two sequences observed.

\subsection{Reactive and Active Power}

Figure 8 shows that the reactive and active power analysis differentiates appliances in the P-Q plane. In Figure 8(a) the desktop and laptop are found in 

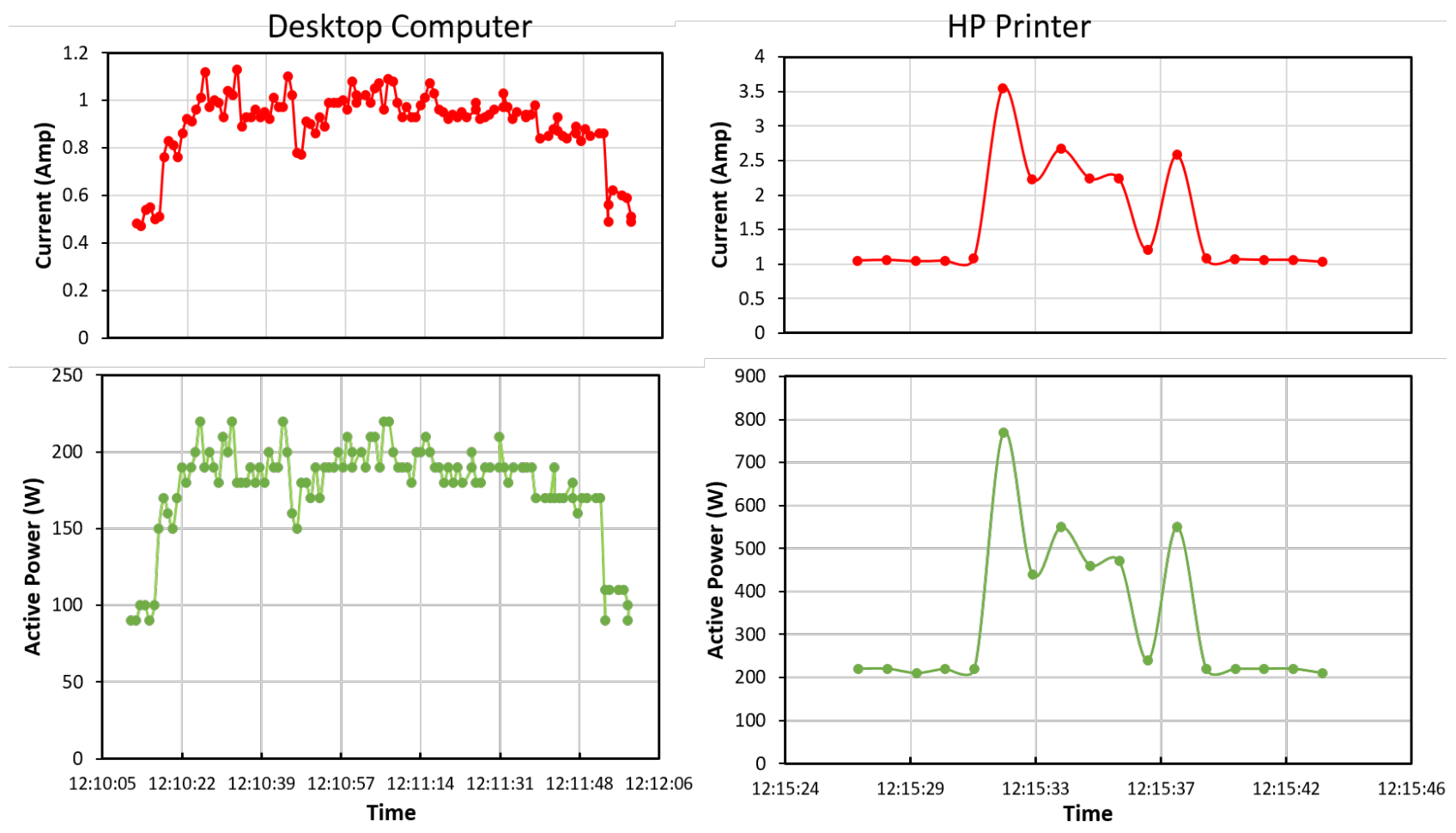

Figure 5. Current and active power for desktop computer and HP printer.
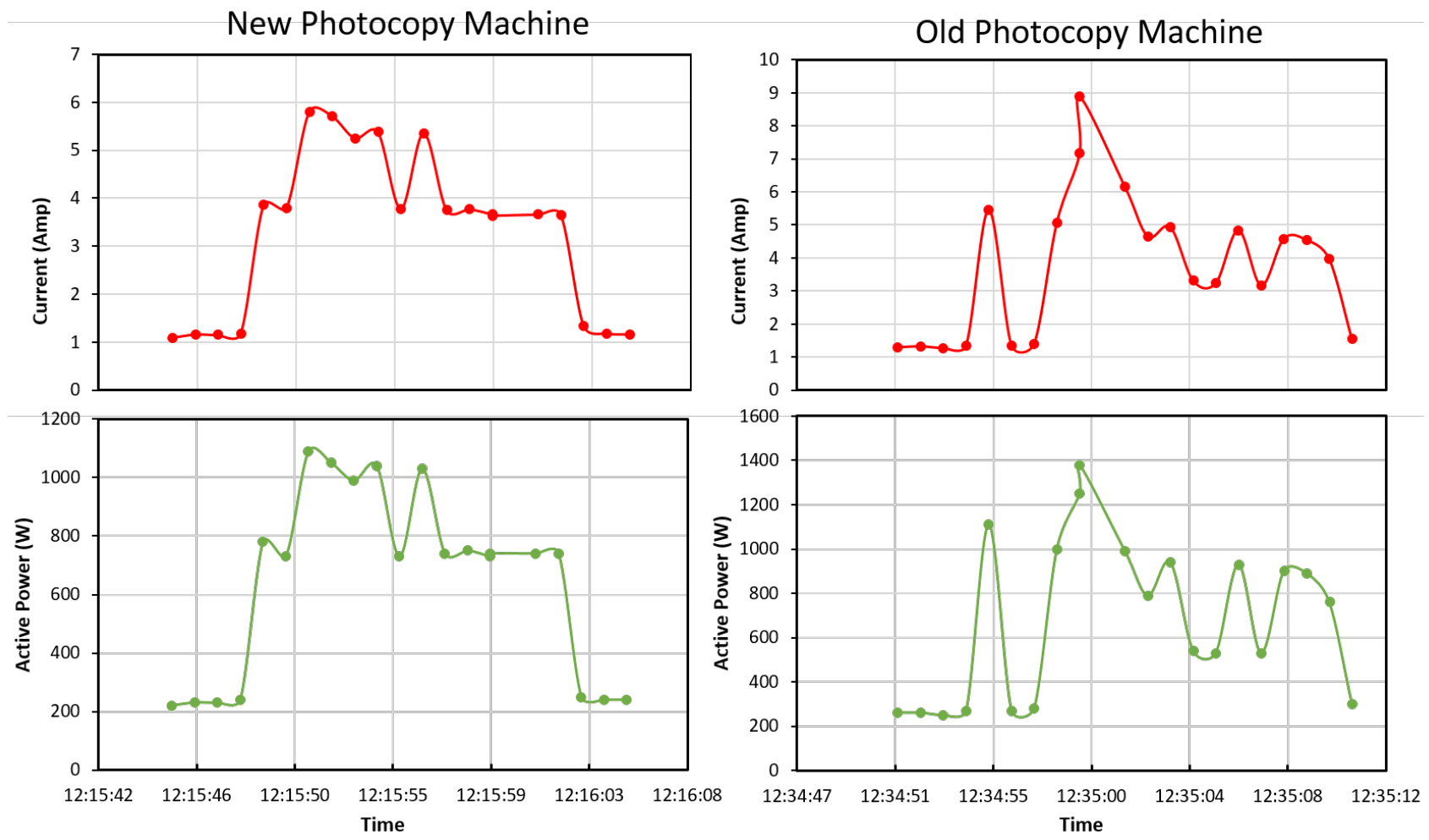

Figure 6. Current and active power for the photocopy machines.

the upper positive-axis region with an approximate reactive power of 70 AVR while tube lights are found in the lower negative-axis region with an average 


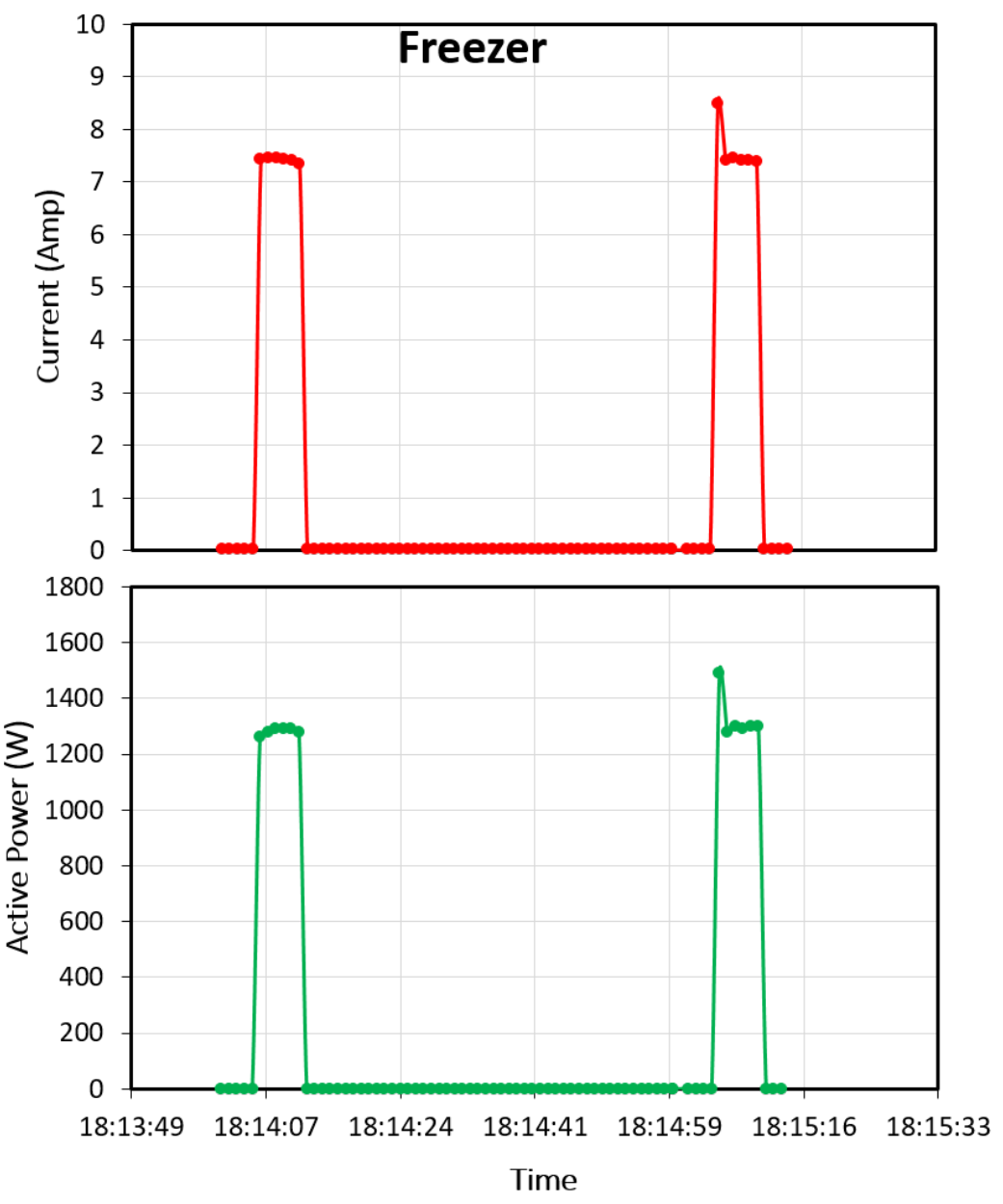

Figure 7. Current and active power for a freezer.

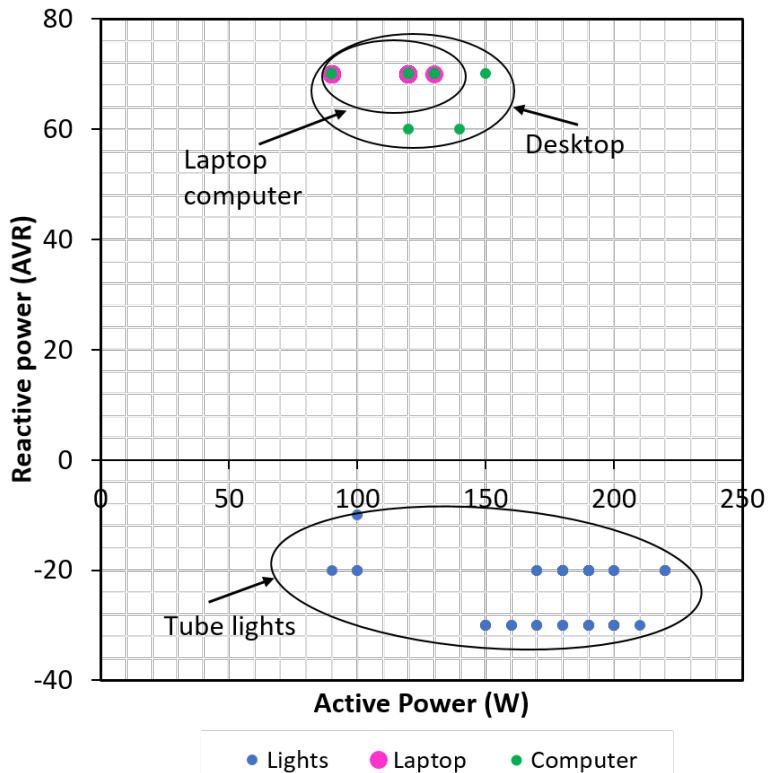

(a)

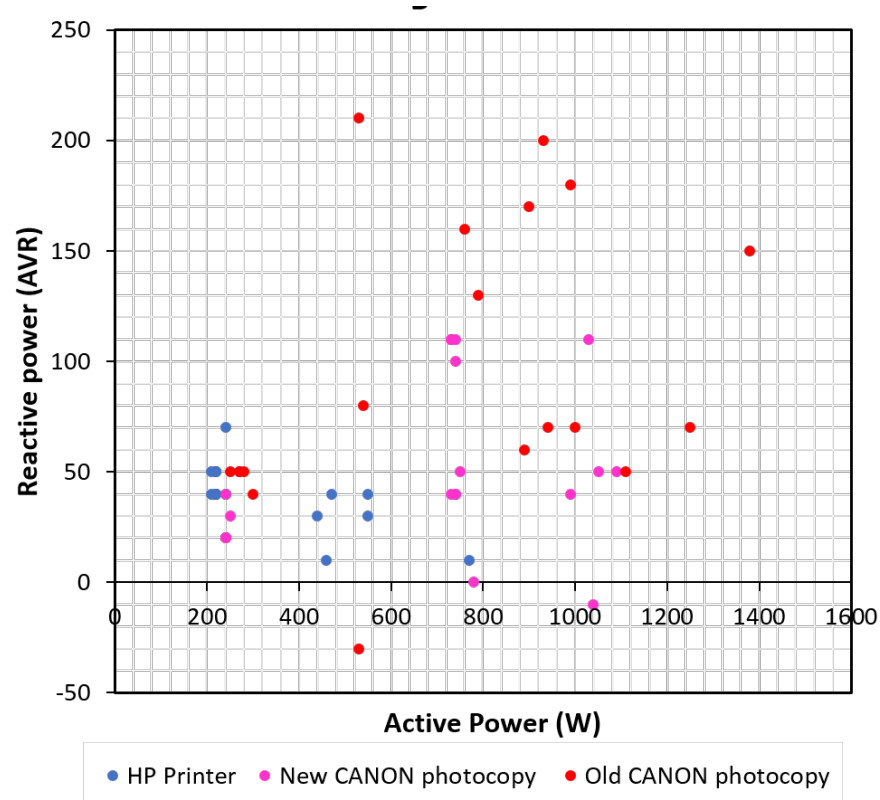

(b)

Figure 8. Active and reactive power of electric loads in administration block. 
reactive power of $-20 \mathrm{AVR}$. Figure 8 (b) shows the spatial view of HP printer, New CANON and old photocopy machines which are presented by blue, pink and red color respectively. In Figure 8 (b) the reactive power is observed to be high for old Canon photocopy machine followed by new photocopy machine and the last is printer.

\subsection{Operation State Results}

\subsubsection{Printer and Photocopy Machine}

Figure 9 illustrates the observed current and active power for the printer and new photocopy machine operating in different conditions. Looking at the Figure 9 it is clear that the amount of current and active power used for photocopying one copy is higher as compared to printing one page. However, the active power signature is the same as current for both machines. The maximum printing current and active power was found to be $3.5 \mathrm{~A}$ and $700 \mathrm{~W}$ respectively. On the other hand, maximum photocopying current and active power was found to be $5.8 \mathrm{~A}$ and $1100 \mathrm{~W}$ respectively.

\subsubsection{Photocopy Machine}

When an electric load such as the photocopy machine is turned on the current waveform experiences high fluctuations at the time of switch ON. Those fluctuations need to be captured in a suitable format so that they can be used to automatically detect the event of switch ON [20]. As such this study also makes the comparative of all states using photocopy machine. Figure 10 illustrate the
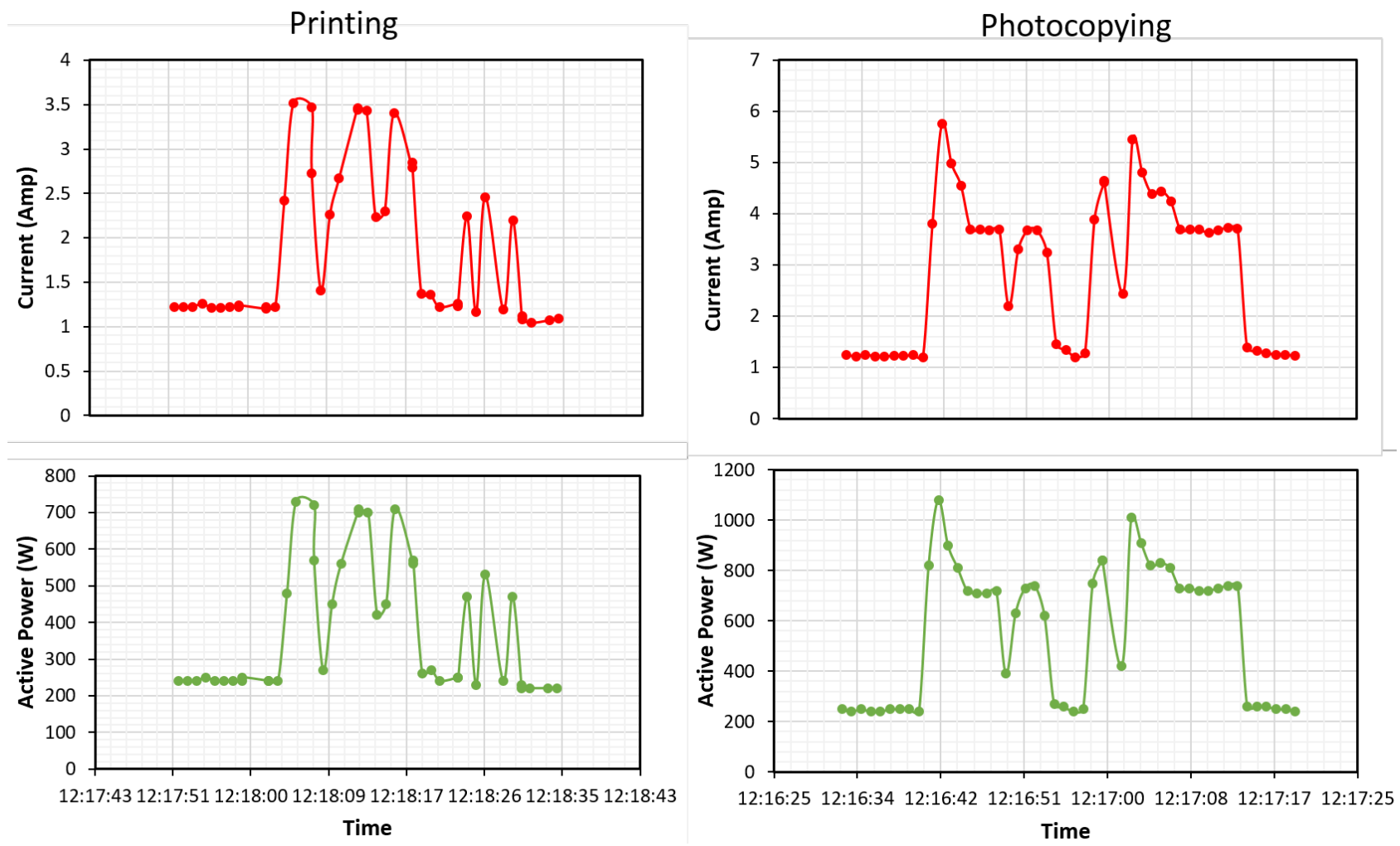

Figure 9. Comparison of current and active power for printing and photocopying. 

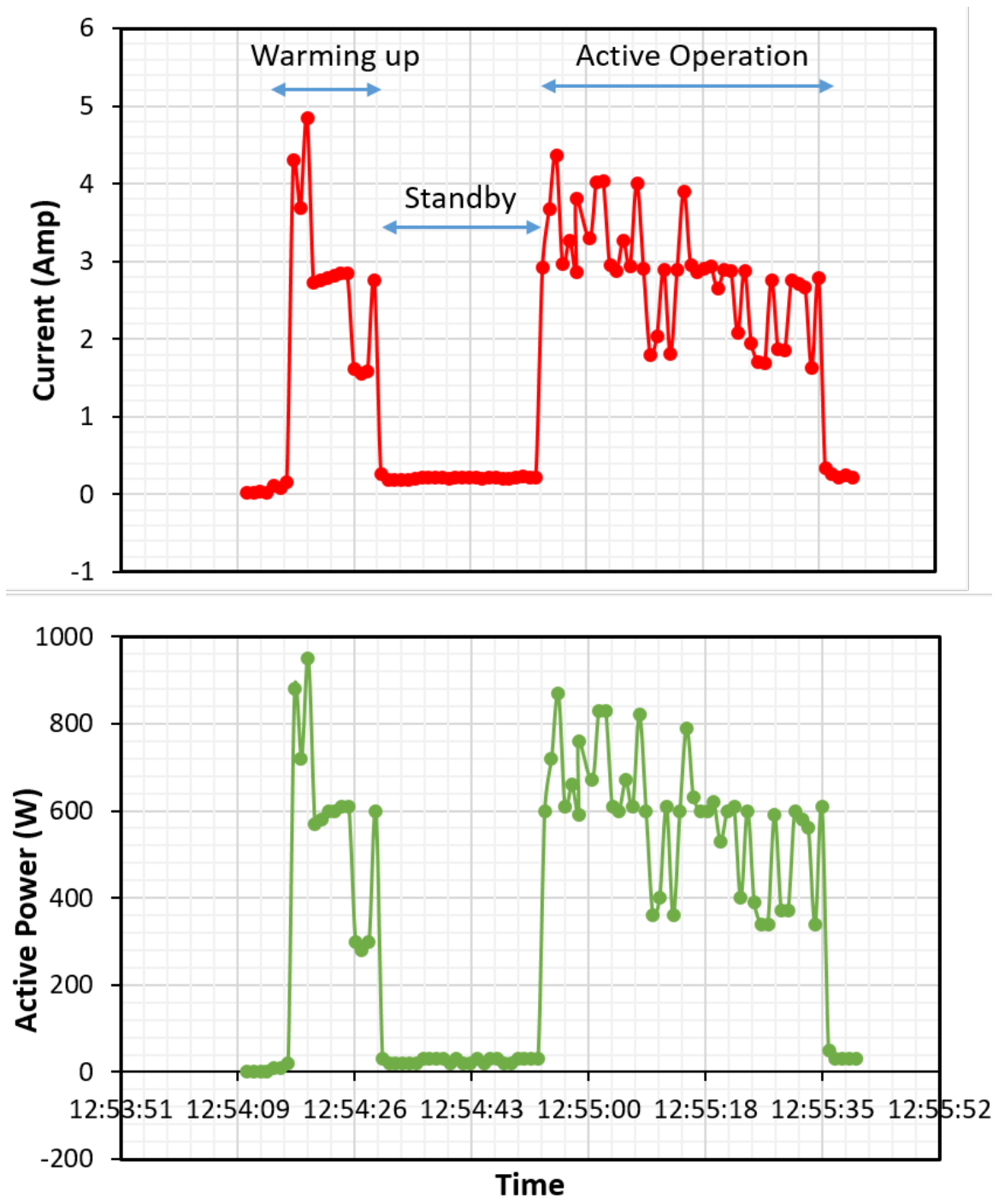

Figure 10. Current and active power for a photocopy machine.

absolute magnitude values of the current and active power signals of photocopy machine in warm-up, standby and active operation states. Analysis of this plot indicates that the high fluctuations of current and active power can be observed at the time of warm-up state (switch ON).

\section{Conclusion}

This paper presents load identification of school electrical energy consumption in different operation states. The goal is to identify electrical appliances and working style which will then help end users of electric energy to monitor the consumption and hence bring the intended energy benefits. The results of load identification indicate that some appliances could consume more electric energy in the energization state than in active operation state (e.g. photocopy machine, printer, and freezer). Further, old photocopy machines were observed to consume more power as compared to the new one. Future work will collect more data with more loads and study both switch ON and switch OFF signals to explore load signa- 
ture analysis methodologies. Another area for future research is to develop demand side management strategies by integrating the load signatures results with the impact that electricity has on the quality of life in the context of universal access of energy for remote rural communities.

\section{Acknowledgements}

The authors would like to thank Nelson Mandela African Institution of Science and Technology for the sponsorship. Funding from National Science Foundation (NSF), Cultivating Responsible Wellbeing (CRWS) project (award number 1449489) made possible the collaboration with University of Puerto Rico-Mayagüez (UPRM). We are also pleased to acknowledge valuable discussions and information from Ngarenanyuki Secondary School staff.

\section{References}

[1] Basu, K., Debusschere, V. and Bacha, S. (2012) Load Identification from Power Recordings at Meter Panel in Residential Households. 2012 XXth International Conference on Electrical Machines (ICEM), Marseille, 2-5 September 2012, 2098-2104.

[2] Huang, Y. and Yang, H. (2012) A Method Based on K-Means and Fuzzy Algorithm for Industrial Load Identification. 2012 Asia-Pacific Power and Energy Engineering Conference, Shanghai, 27-29 March 2012, 1-4.

[3] Srinivasan, D., Ng, W. and Liew, A. (2006) Neural-Network-Based Signature Recognition for Harmonic Source Identification. IEEE Transactions on Power Delivery, 21, 398-405. https://doi.org/10.1109/TPWRD.2005.852370

[4] Zoha, A., et al. (2012) Non-Intrusive Load Monitoring Approaches for Disaggregated Energy Sensing: A Survey. Sensors, 12, 16838-16866. https://doi.org/10.3390/s121216838

[5] Meehan, P. (2015) An Efficient Scalable Time-Frequency Method for Tracking Energy Usage of Domestic Appliances Using a Two-Step Classification Algorithm. PhD Thesis, Dublin City University, Dublin.

[6] Amenta, V. and Tina, G.M. (2015) Load Demand Disaggregation Based on Simple Load Signature and User's Feedback. Energy Procedia, 83, 380-388. https://doi.org/10.1016/j.egypro.2015.12.213

[7] Chan, W., So, A.T. and Lai, L. (2000) Harmonics Load Signature Recognition by Wavelets Transforms. Proceedings of 2000 International Conference on Electric Utility Deregulation and Restructuring and Power Technologies, London, 4-7 April 2000, 666-671. https://doi.org/10.1109/DRPT.2000.855745

[8] Moro, J.Z., et al. (2013) A Home Appliance Recognition System Using the Approach of Measuring Power Consumption and Power Factor on the Electrical Panel, Based on Energy Meter ICs. Circuits and Systems, 4, 245

https://doi.org/10.4236/cs.2013.43033

[9] Du, Y., et al. (2010) A Review of Identification and Monitoring Methods for Electric Loads in Commercial and Residential Buildings. 2010 IEEE Energy Conversion Congress and Exposition, Atlanta, 12-16 September 2010, 4527-4533.

[10] Mouelhi, F., Sethom, H.B.A. and Slama-Belkhodja, I. (2014) Fast Event Detection Method for Residential Load Demand Side Management. 2014 International Conference on Electrical Sciences and Technologies in Maghreb (CISTEM), Tunis, 3-6 November 2014, 1-7. 
[11] Chang, H.-H. and Lin, C.-L. (2010) A New Method for Load Identification of Nonintrusive Energy Management System in Smart Home. 7 th International Conference on E-Business Engineering, Shanghai, 10-12 November 2010, 351-357.

[12] Chang, H.-H., et al. (2012) A New Measurement Method for Power Signatures of Nonintrusive Demand Monitoring and Load Identification. IEEE Transactions on Industry Applications, 48, 764-771. https://doi.org/10.1109/TIA.2011.2180497

[13] Najmeddine, H., et al. (2008) State of Art on Load Monitoring Methods. 2nd International Power and Energy Conference, Johor Bahru, 1-3 December 2008, 1256-1258.

[14] Bacurau, R., et al. (2015) Experimental Investigation on the Load Signature Parameters for Non-Intrusive Load Monitoring. Przegląd Elektrotechniczny, 91, 86-90. https://doi.org/10.15199/48.2015.08.22

[15] Guzel, T. and Ustunel, E. (2015) Principal Components Null Space Analysis Based Non-Intrusive Load Monitoring. Electrical Power and Energy Conference, London, 26-28 October 2015, 420-423.

[16] Cheng, J.W., et al. (2012) An Alternative Use of Power Quality Information-Load Signature Studies \& Applications. 15th International Conference on Harmonics and Quality of Power, Hong Kong, 17-20 June 2012, 150-155.

[17] Carmeli, M., et al. (2015) Hybrid Micro-Grid Experimental Application in Tanzania. International Conference on Clean Electrical Power, Taormina, 16-18 June 2015, 534-541.

[18] Mario, E.B., et al. (2010) Enhancing Electricity Audits in Residential Buildings with Nonintrusive Load Monitoring. Journal of Industrial Ecology, 14, 844-858.

[19] Singh, M., et al. (2015) Residential Load Signature Analysis for Their Segregation Using Wavelet-SVM. In: Power Electronics and Renewable Energy Systems, Springer, Berlin, 863-871. https://doi.org/10.1007/978-81-322-2119-7_84

[20] Gillman, M.D., et al. (2014) Energy Accountability using Nonintrusive Load Monitoring. IEEE Sensors Journal, 14, 1923-1931. https://doi.org/10.1109/JSEN.2014.2305911

Submit or recommend next manuscript to SCIRP and we will provide best service for you:

Accepting pre-submission inquiries through Email, Facebook, LinkedIn, Twitter, etc. A wide selection of journals (inclusive of 9 subjects, more than 200 journals)

Providing 24-hour high-quality service

User-friendly online submission system

Fair and swift peer-review system

Efficient typesetting and proofreading procedure

Display of the result of downloads and visits, as well as the number of cited articles

Maximum dissemination of your research work

Submit your manuscript at: http://papersubmission.scirp.org/

Or contact jpee@scirp.org 